\title{
Percepção sobre meio ambiente por alunos das séries iniciais do Ensino Fundamental: considerações à luz de Marx e de Paulo Freire
}

\section{Perception of the environment by students of elementary school: considerations in the light of Marx and Paulo Freire}

\author{
Luciana dos Santos Garrido $^{1}$. Rosane Moreira Silva de Meirelles ${ }^{2}$
}

\begin{abstract}
Resumo: A Educação Ambiental tem sido apontada há algum tempo como uma grande aliada para solucionar a crise ambiental vivida atualmente. Esse estudo teve como objetivo discutir a percepção de meio ambiente apresentada por alunos dos $1^{\circ}$ e $5^{\circ}$ anos do Ensino Fundamental com referência na Educação Ambiental Crítica. Os instrumentos de coleta de dados foram desenhos, entrevistas e análise de gravuras. Os resultados mostraram que os alunos de $1^{\circ}$ e $5^{\circ}$ anos do Ensino Fundamental apresentam uma percepção naturalista de meio ambiente. Entretanto, os alunos também demonstraram perceber problemas ambientais presentes no cotidiano. Portanto, os resultados apontaram que, embora os alunos ainda tenham percepção fragmentada de meio ambiente, eles percebem muitos aspectos relacionados às suas vidas. Esperamos que este estudo possa fomentar a discussão do trabalho efetivo sobre a Educação Ambiental Crítica desde os primeiros anos de escolaridade.
\end{abstract}

Palavras-chave: Ensino Fundamental. Meio ambiente. Educação ambiental crítica.

\begin{abstract}
Environmental education has been identified for some time as a great ally to solve the current environmental crisis. This study has the goal of discussing the perceptions about the environment, produced by students of the 1 st and 5 th years of elementary school with reference to Critical Environmental Education. The instruments of data collection were interviews and drawings. The results showed that students of 1 st and 5 th years of elementary school have a perception of natural environment. However, students also demonstrated that they perceive environmental problems in the everyday. Therefore, we conclude that, although students still have a fragmented perception of the environment, they perceive many aspects related with their lives. We hope this study will encourage discussion about Critical Environmental Education from the earliest years of schooling.
\end{abstract}

Keywords: Elementary school. Environment. Critical environmental education.

\footnotetext{
${ }^{1}$ Laboratório de Inovações em Terapias, Ensino e Bioprodutos, Fundação Oswaldo Cruz (Fiocruz), Avenida Brasil, n. 4.365, Manguinhos, CEP 21040-3601, Rio de Janeiro, RJ, Brasil. E-mail: <lucianagarrido.bio@hotmail.com> ${ }^{2}$ Programa em Ensino em Ciências da Saúde e do Meio Ambiente, Fundação Oswaldo Aranha (Unifoa), Volta Redonda, RJ, Brasil.
} 


\section{Introdução}

A crise ambiental atual aponta para um momento histórico vivido pelo ser humano. Uma crise que tem, em suas raízes, a desequilibrada relação do ser humano com a natureza e do ser humano com outros seres humanos (QUINTAS, 2004). Essa crise ambiental é algo que não tem passado despercebida pelas sociedades, causando grande preocupação em todo o mundo. Embora um grande esforço tenha sido empenhado para camuflar as verdadeiras causas dessa crise, é sabido que as ações humanas são a principal responsável por essa crise, e que essas ações têm trazido sérias consequências à vida do planeta (PINOTTI, 2010). Em seguida à Revolução Científica, surgiu, no século XVIII, algo que, para alguns autores, seria crucial para alavancar a crise ambiental que conhecemos hoje: a Revolução Industrial. Além de trazer um novo modo de produção de trabalho e de vida, a Revolução Industrial gerou, também, o afastamento do ser humano em relação à natureza (BRÜGGER, 2004). O progresso e o desenvolvimento trazidos pelo modelo econômico atual prometiam uma melhor qualidade de vida para todos, porém o que vimos foi apenas uma pequena quantidade de pessoas sendo beneficiadas (MORIN; CIURANA; MOT'TA, 2009). Essas e outras modificações contribuíram para formar os paradigmas que regem a sociedade atual e que a aprisionam a um modelo que, em muitos casos, tem se mostrado extremamente nocivo (GUIMARÃES, 2007). O cientificismo cartesiano, o reducionismo, o antropocentrismo, o consumismo, o individualismo, o tecnicismo e o saber fragmentado são alguns dos aspectos característicos da sociedade que impulsionaram e que ainda agravam a crise ambiental (BRÜGGER, 2004; GUIMARÃES, 2004, 2007).

É nesse contexto que a Educação Ambiental Crítica surge para contribuir com o resgate de valores essenciais para uma nova cidadania, assumindo um olhar integrado das relações entre seres humanos e a natureza e entre seres humanos e seus semelhantes (GUIMARÃES, 2004). Brügger (2004) e Reigota (2009) concordam que um passo inicial para a Educação Ambiental (EA) é a correta construção do significado de meio ambiente. Para esses autores, o conceito de meio ambiente deve considerar os aspectos naturais e sociais, observando todas as relações entre os fatores biológicos, sociais, físicos, econômicos, culturais e históricos. A EA tem a característica de ser contínua e deve ser discutida no âmbito da educação formal em todos os níveis. Segundo Pinotti (2010, p. 172), "a conscientização ecológica exige, antes de tudo, educação, que, por sua vez, demanda anos de estudo [...]”.

Diante desse cenário, em nosso trabalho, surgiu a preocupação em compreender, por meio da discussão sobre a percepção de meio ambiente, como a EA estaria contribuindo para a formação do conceito de meio ambiente entre os alunos do $1^{\circ}$ segmento do Ensino Fundamental.

\section{Fundamentação Teórica}

Embora o termo Educação Ambiental nos remeta a uma educação para o meio ambiente, as formas como essa educação será pensada e praticada podem implicar diferentes práticas de EA. Por isso, é necessário estabelecer quais concepções teórico-filosóficas estão subjacentes à EA abordada no presente trabalho.

As diferentes maneiras de como a EA tem sido trabalhada, na verdade, revelam diferentes percepções sobre o meio ambiente construídas ao longo dos anos. A ideia de percepção 
adotada no presente estudo é aquela na qual se conjuga a influência pelos sentidos e, também, pelas cognições. Segundo Vygotsky (1988 apud PEREIRA, 2001), a percepção de um objeto ou fenômeno se dá de acordo com o significado atribuído pelo sujeito, tratando-se, portanto, de uma realidade conceituada e não material. Para Piaget (1924 apud VIGOTSKY, 1989), a percepção se desenvolve durante a idade escolar, e , com o desenvolvimento da linguagem, a criança passa a uma percepção orientada pelas palavras.

De acordo com Hoeffel e Fadini (2007), as percepções de diferentes atores são construídas a partir de suas experiências, e são moldadas com referência nos contextos histórico e cultural. Por essa razão, membros de uma mesma cultura podem expressar diferentes percepções sobre um mesmo objeto. Esses autores ainda acrescentam que, no mundo das percepções, não deve haver certo ou errado, apenas uma ponte entre diferenças na expectativa de contribuir para a solução das questões ambientais. Marin, Oliveira e Comar (2003) não tratam a percepção apenas pelo mundo dos sentidos, e entendem que as percepções são influenciadas por fatores como: memória, afetividade, imaginário e experiências. Conhecer as diferentes percepções dos indivíduos sobre o meio ambiente auxilia na elaboração e prática de programas de EA (HOEFFEL; FADINI, 2007).

As concepções trazidas pela EA não são neutras, e sim ideológicas (TOZONI-REIS, 2008). Nesse estudo foram utilizados como referenciais teóricos: a Teoria Marxista, de Karl Marx, as ideias do educador Paulo Freire e os conceitos da Teoria da Complexidade de Edgar Morin.

O filósofo Karl Marx buscava superar os padrões da ciência e da filosofia dominantes em sua época. Ele lutava por uma sociedade onde prevalecesse o interesse coletivo em lugar do individualismo (LOUREIRO, 2006). Uma das preocupações de Marx (1963) era pensar as relações entre os seres humanos e entre esses e a natureza. Para ele, o ser humano era parte integrante da natureza. $\mathrm{O}$ autor entendia que a natureza era como uma unidade complexa e dinâmica, não podendo ser separada do ser humano. Para ele, um está vinculado ao outro sem estar se reduzindo ao outro. Em sua teoria, Marx (1963) apresenta, com detalhes, as formas de exploração e dominação que são expressas por meio do capitalismo, e como essas relações influenciam o modo de vida do ser humano e, também, as relações do ser humano com a natureza. Afirma que esse modo de produção e reprodução na vida da sociedade contribuiu, e muito, para a ruptura da relação homem-natureza.

Segundo Loureiro (2006), uma das contribuições marxistas para a educação está em afirmar que a educação é um produto, ao mesmo tempo em que é produtora das relações sociais do seu contexto. É com base nessa educação transformadora e emancipatória, que instrumentaliza o sujeito a exercer sua cidadania em busca dessa sociedade mais justa e igualitária, que podemos assistir ao encontro das ideias de Karl Marx e de Paulo Freire.

Paulo Freire desenvolveu o seu pensamento pedagógico tendo como compromisso a formação crítica do sujeito e a transformação social. Para Freire (2005), a educação estava ligada ao conceito da palavra grega Paideia. Essa palavra, na civilização grega, tinha o sinônimo de educar e civilizar. A Paideia é uma palavra que expressa o processo educativo numa perspectiva do holismo, no qual a formação do indivíduo acontece atrelada aos aspectos culturais, econômicos, históricos e outros, que fazem parte da vida do sujeito (BRÜGGER, 2004).

A pedagogia de Paulo Freire encontra-se com a dialética de Marx por compartilharem algumas concordâncias a respeito do ser humano. A primeira concordância está no fato de ambos darem extrema importância ao diálogo; para eles não existe uma dicotomia entre o ser humano 
e o mundo e, por consequência, entre o ser humano e a natureza. Ambos consideravam o ser humano como um todo, constituído por todas as suas dimensões: cultural, social, política e econômica. Para eles, a educação não deve ser mera reprodutora da sociedade, mas deve ser um caminho por onde o indivíduo possa se perceber dentro de uma realidade concreta e histórica (PERNAMBUCO; SILVA, 2006).

Outra característica compartilhada entre Marx e Freire está na importância da coletividade. Segundo Pernambuco e Silva (2006), o pensamento de Paulo Freire tinha como objetivo contribuir para a formação crítica do sujeito, para que eles pudessem transformar a sociedade com ações coletivas. Mais uma semelhança encontrada entre Marx e Freire citada aqui é a busca da transformação da sociedade: ambos buscavam contribuir para a construção de uma nova sociedade, uma sociedade mais justa e equilibrada.

A busca pela construção coletiva de uma nova sociedade era uma das principais marcas do pensamento de Marx (LOUREIRO, 2006). A superação dessa individualidade, rejeitada por Marx e Freire, é necessária segundo Tozoni-Reis (2006). Para a construção de soluções para os problemas ambientais, é preciso superar a lógica antropocêntrica que predomina atualmente, onde o ser humano quer dominar a natureza e, também, outros seres humanos a fim de satisfazer suas vontades.

Embora Marx e Freire não tenham se dedicado à EA especificamente, consideramos que suas ideias ajudam a compreender e contribuem para essa educação que chamamos de Ambiental.

Coaduna-se com as ideias de integração entre o ser humano e a natureza defendidas por Marx e Freire, a Teoria da Complexidade que, segundo Tozoni-Reis (2008), foi desenvolvida, sobretudo, por Morin. A Teoria da Complexidade se contrapõe à fragmentação e ao individualismo de nossa sociedade. Nesse sentido, é importante salientar que a mesma se aplica à formação do indivíduo como um todo, constituindo um novo olhar sobre o mundo. A proposta do pensamento complexo vai além da articulação e ligação dos saberes. O pensamento complexo faz parte, também, do âmbito social e humano, e se estende às dimensões éticas, políticas e econômicas. Educar com base no pensamento complexo é uma urgência nos dias de hoje, e requer mudanças na forma de pensar, de educar e de conhecer (MORIN; CIURANA; MOTTA, 2009).

\section{A Educação Ambiental Crítica}

O adjetivo "crítico" surgiu ao lado do nome da EA como uma necessidade de diferenciação do que pode ser chamada de EA Conservadora, que se manifesta em ações que buscam superar a crise ambiental em que vivemos usando a mesma lógica dominante que gerou a crise. Trata-se de uma EA guiada pelos mesmos paradigmas que resultaram na dicotomia sociedadenatureza (GUIMARÃES, 2004).

A vertente crítica da EA surgiu a partir da década de 1980, e originou-se das pedagogias críticas e emancipatórias. Despontou com a forte característica dialética que permite acumular contribuições de outras teorias e correntes teóricas (LOUREIRO, 2004). A EA Crítica se caracteriza por ser uma prática social que compreende as questões ambientais vinculadas aos 
processos sociais na leitura de mundo. $\mathrm{O}$ ser humano se relaciona na natureza por mediações sociais que são construídas ao longo de sua história.

A EA Crítica é considerada, por Reigota (2009), Guimarães (2007) e Loureiro (2004), como uma educação política, pelo fato de estar preocupada em promover a cidadania, a liberdade e a autonomia, proporcionando, aos indivíduos, a possibilidade de fazer escolhas, intervir e transformar sua realidade na busca de uma sociedade democrática, justa e igualitária para todos.

A EA Crítica se definiu pela necessidade de rompimento com o modelo de vida adotado atualmente em nossa sociedade impregnada de valores individualistas e consumistas. (LOUREIRO, 2007). Outros autores concordam com Loureiro quando assumem que os paradigmas que regem nossa sociedade e que focam sua compreensão na parte, e não no todo, são os desencadeadores da crise ambiental que vivemos hoje (BRÜGGER, 2004; GUIMARÃES, 2007; REIGOTA, 2009).

Vários trabalhos têm mostrado as representações de meio ambiente de determinados grupos, reconhecendo a importância de se conhecerem percepções de docentes e discentes (BARCELLOS et al., 2005; GUIMARÃES, 2002; REIGADA; TOZONI-REIS, 2004; SCHWARZ; SEVEGNANI; ANDRÉ, 2007).

A partir dessa reflexão e partindo do pressuposto que os alunos das séries iniciais do Ensino Fundamental ainda possuem uma percepção muito superficial do meio ambiente e seus componentes, esse estudo teve como objetivo discutir a percepção de alunos do $1^{\circ}$ e $5^{\circ}$ anos do Ensino Fundamental sobre o meio ambiente e seus problemas.

\section{Desenho metodológico}

A pesquisa desenvolvida teve um caráter descritivo, e seus resultados foram analisados adotando uma abordagem qualitativa. A pesquisa qualitativa busca interpretar dados da realidade a partir da perspectiva dos pesquisados. Como ela representa dados de uma realidade específica, a pesquisa qualitativa existe num contexto histórico-social e temporal-espacial (LUDKE; ANDRÉ, 1986; NEVES, 1996). A pesquisa foi desenvolvida em uma escola municipal situada no município de Duque de Caxias, estado do Rio de Janeiro. A escola encontra-se em uma localidade chamada São Bento, que abriga a Área de Proteção Ambiental do São Bento (APA), e por ela passam os rios Iguaçu e Sarapuí, além de manguezais e de uma área alagada que serve para absorver as cheias dos rios. Também nesse local encontra-se o Museu Vivo do São Bento. A localidade chamada São Bento localiza-se próxima ao bairro Parque Fluminense, e sofre com problemas de abastecimento de água e com enchentes no período de chuvas. Para essa pesquisa, foram selecionadas uma turma do $1^{\circ}$ ano e uma turma do $5^{\circ}$ ano do Ensino Fundamental, escolhidas por representarem o início e o final do $1^{\circ}$ segmento do Ensino Fundamental (antigo primário). A coleta de dados foi realizada entre os meses de fevereiro e agosto do ano de 2011. Os instrumentos de coleta de dados utilizados no estudo foram a elaboração de desenhos, entrevistas e análise de gravuras. A utilização de mais de uma técnica tem por objetivo compreender determinada realidade a partir de uma análise multidimensional. O confrontamento dos dados, obtidos por meio de diferentes técnicas, confere uma validade maior às informações coletadas (SOUZA; ZIONI, 2003). 


\section{Resultados e discussão}

Participaram da pesquisa um total de 43 alunos, tendo faixa etária entre seis e sete anos para a turma de $1^{\circ}$ ano, e nove a 14 anos para a turma de $5^{\circ}$ ano.

\section{Análise dos desenhos}

Foram elaborados 41 desenhos pelos alunos, sendo 17 por alunos do $1^{\circ}$ ano e 24 por alunos do $5^{\circ}$ ano. A elaboração dos desenhos ocorreu após a leitura do livro Vamos abraçar o mundinho (BELLINGHAUSEN, 2002) e roda de conversa. Foi solicitado, aos alunos, que fizessem um desenho que retratasse o meio ambiente ao redor da sua casa, e os alunos foram estimulados a desenhar independente das limitações estéticas. Após a elaboração dos desenhos, os alunos apontaram individualmente todos os elementos contidos.

Iniciou-se a análise dos desenhos pela identificação dos elementos presentes. A técnica de análise ocupou-se apenas em descrever os elementos representados nos desenhos, com a finalidade de compreender a relação dos alunos com o meio ambiente. Inicialmente, os elementos encontrados nos desenhos foram incluídos em duas categorias estabelecidas de acordo com os Parâmetros Curriculares Nacionais Meio Ambiente e Saúde - PCN (BRASIL, 1997): elementos naturais e elementos artificiais. Embora outros parâmetros pudessem ser utilizados para definir essas categorias, nesse estudo, optou-se pelo recorte baseado nos PCN Meio Ambiente e Saúde. Feita essa primeira categorização, pôde-se perceber que a presença de elementos naturais contidos nos desenhos era maior que a presença de elementos artificiais As figuras 1 e 2 são exemplos de desenhos elaborados por alunos do $1^{\circ}$ e $5^{\circ}$ anos.

Figura 1. Desenho representando casa, grama, garagem e cachorro como elementos do meio ambiente

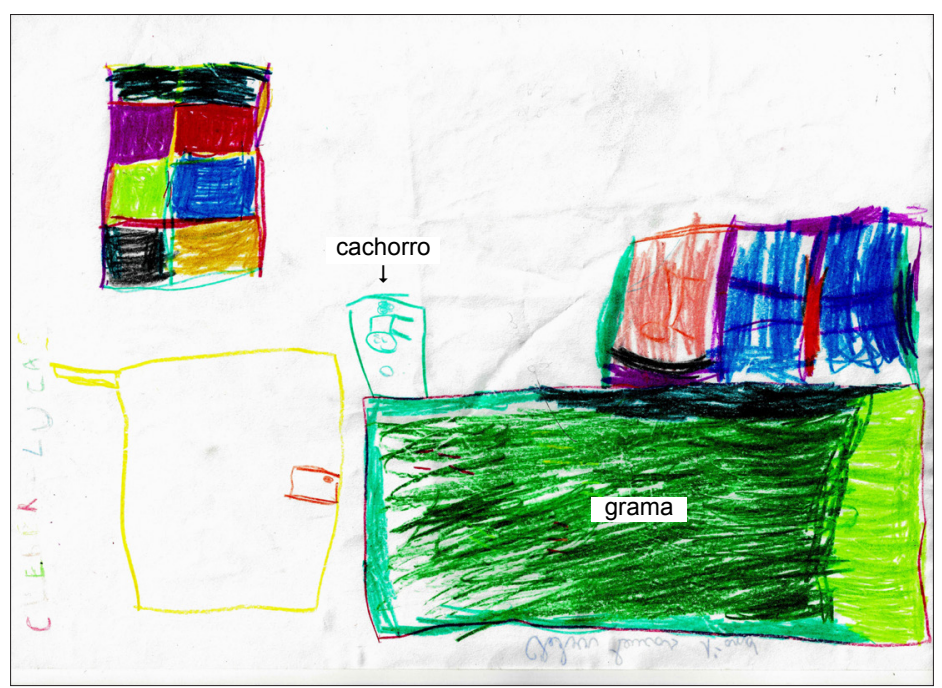

Fonte: Desenho de um aluno do $1^{\circ}$ ano do Ensino Fundamental 
Figura 2. Desenho representando casa, rua, árvore, sol, nuvens, grama e pedras como elementos do meio ambiente

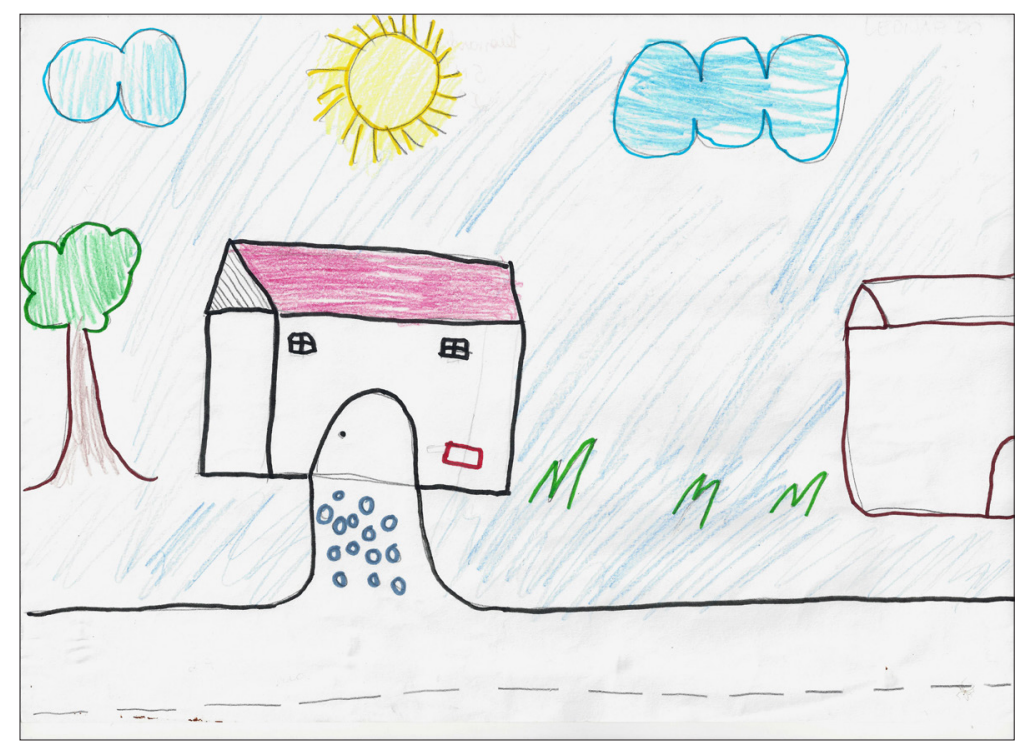

Fonte: Desenho de um aluno do $5^{\circ}$ ano do Ensino Fundamental

Posteriormente, buscando compreender como o ser humano era percebido como meio ambiente, os elementos naturais foram subdivididos em elementos bióticos e abióticos, segundo definição do PCN Meio Ambiente e Saúde (BRASIL, 1997), e o resultado encontrado pode ser observado no Gráfico 1.

Gráfico 1. Seres Bióticos presentes nos desenhos dos $1^{\circ}$ e $5^{\circ}$ anos do Ensino Fundamental

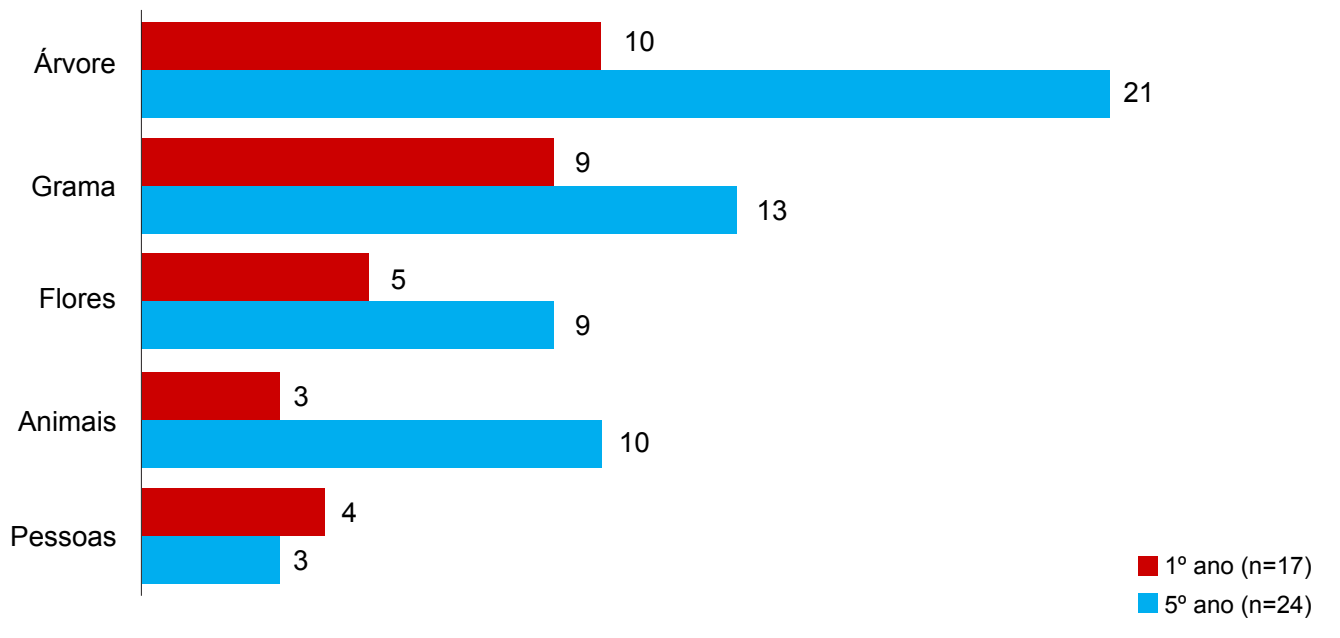

Fonte: Elaborado pelas autoras a partir dos dados obtidos pela análise da pesquisa 
No Gráfico 1, observa-se que, ao representarem o meio ambiente ao redor de sua casa, os alunos das turmas de $1^{\circ}$ e $5^{\circ}$ anos dão maior enfoque aos elementos da flora (árvores, grama e flores) do que aos elementos da fauna ou à presença humana. Estes dados sugerem, a partir da análise dos desenhos, que a maioria dos alunos pesquisados apresenta uma percepção naturalista do meio ambiente. Para classificar as percepções identificadas nos desenhos, seguimos a classificação dada por Reigota (2007). Segundo esse autor, a visão naturalista é aquela com predominância de elementos naturais, tais como os elementos bióticos e abióticos. Esse resultado sobre a percepção dos alunos sobre o meio ambiente coincide com os resultados de outros estudos. Em um estudo desenvolvido por Martinho e Talamoni (2007), 70\% dos alunos da quarta série do Ensino Fundamental apresentavam visão naturalista do ambiente. Pedrini, Costa e Ghilardi (2010) observaram, durante desenvolvimento de projetos de EA, que crianças e pré-adolescentes em vulnerabilidade social também apresentam percepção maior de símbolos naturais. De forma similar, Aires e Bastos (2011) identificaram forte presença de elementos naturais nas representações sobre meio ambiente levantadas por meio da análise de mapas mentais de alunos da rede básica da cidade de Palmas, TO. Interessante ressaltar que, embora possa haver diferenças na ordem em que os elementos fauna e flora são representados, a presença do ser humano é escassa e a percepção naturalista permanece.

Após a realização dos desenhos, foi solicitado, aos alunos, que cada um citasse um componente que eles consideravam pertencer ao meio ambiente. A pesquisadora registrou, por escrito, as falas dos alunos em um cartaz. Dos 18 alunos da turma de $1^{\circ}$ ano presentes, 14 participaram. Desses, nove citaram elementos naturais (cachorro, cavalo, árvore, mato, uva, rio, chuva, água e sol), e cinco citaram elementos artificiais (piscina, moto, carro, boneca e lixo). $\mathrm{Na}$ turma do $5^{\circ}$ ano, de um total de 24 alunos presentes, 14 citaram elementos naturais (árvore, flores, plantação, animais, fruta, pessoas, pássaros, inseto, mar, água, cachoeira, terra, sol e ar) e cinco citaram elementos artificiais (casa, carro, caminhão, cadeira e avião). Os resultados demonstraram que, mais uma vez, os alunos de ambas as turmas apresentaram a mesma percepção naturalista do meio ambiente, tal qual havia sido retratada nos desenhos.

\section{Análise das entrevistas}

As entrevistas realizadas com os alunos de $1^{\circ}$ e $5^{\circ}$ anos também foram submetidas à análise de conteúdo (BARDIN, 2009). As respostas dos alunos foram relacionadas com os temas selecionados para nosso estudo: "lixo", "água” e "relações entre o sujeito e outras pessoas e cuidados que os sujeitos podem atribuir ao meio ambiente". Foram entrevistados 37 alunos, sendo 16 alunos da turma do $1^{\circ}$ ano e 21 alunos da turma de $5^{\circ}$ ano.

$\mathrm{Na}$ primeira parte da entrevista, buscamos conhecer as percepções dos alunos sobre a casa onde vivem e sobre a presença de praças, rios, valas e terreno baldio próximos de suas residências. Segundo Bispo e Oliveira (2007), o lugar e o cotidiano são importantes categorias a serem conhecidas quando se investigam representações sobre meio ambiente, pois, para esses autores, as percepções se constroem em um dado lugar e nas relações do dia a dia. Em relação ao tema "água", perguntamos, aos alunos, como era o abastecimento, armazenamento e utilização da água em suas casas. Todos os alunos afirmaram ter água em suas casas, porém, oito alunos $(50 \%)$ da turma de $1^{\circ}$ ano disseram ter problemas com a falta de água; quatro alunos $(25 \%)$ utilizavam água do poço, e seis alunos (37,5\%) armazenavam água em latões, caixas 
d'água e piscinas. Na turma de $5^{\circ}$ ano, a realidade não é diferente: 12 alunos (57\%) enfrentam problemas com a falta de água; quatro alunos (19\%) revelaram que utilizam água do poço; nove alunos $(43 \%)$ disseram que armazenam água em latões, caixas d'água e cisternas. Com relação ao tema "lixo", identificamos que famílias de alunos de ambas as turmas utilizavam sacolas plásticas provenientes de mercado e comércio em geral para armazenamento do lixo; alguns poucos alunos relataram também armazenar o lixo diretamente em latões. Com relação à coleta do lixo, 32 entrevistados $(86 \%)$ reportaram coleta regular em suas residências, cinco alunos $(13,5 \%)$ relataram que não ocorre coleta de lixo regularmente em suas ruas. Segundo Bastos (2009), 88,9\% das residências do município de Duque de Caxias possuem a coleta regular de lixo, o que mostra que alguns grupos de pessoas $(11,1 \%)$ não são beneficiados ainda por esse serviço. Estudo realizado junto a professores de um distrito de Duque de Caxias também apontou o lixo como um dos problemas ambientais do local (GUIMAR ̃̃ES, 2002). Em nosso estudo, apesar da pouca idade, os alunos, perceberam e relataram a realidade dos fatos inerentes à localidade em que estão inseridos.

O último tema analisado por meio das entrevistas foi: "relações entre o sujeito e outras pessoas e cuidados que os sujeitos podem atribuir ao meio ambiente". Confirmamos nas entrevistas, tal qual observado na análise dos desenhos, forte presença da flora relacionada como elemento do meio ambiente. Apenas quatro alunos $(25 \%)$ da turma de $1^{\circ}$ ano incluíram o ser humano como parte do meio ambiente. $\mathrm{Na}$ análise dos desenhos e das entrevistas dos alunos da turma de $5^{\circ}$ ano, observamos resultados semelhantes àqueles obtidos com alunos da turma do $1^{\circ}$ ano, ou seja, grande percepção da flora e da fauna e pouca percepção do ser humano como elemento do meio ambiente. $\mathrm{Na}$ análise das entrevistas, observamos que cinco alunos $(24 \%)$ da turma de $5^{\circ}$ ano atribuem maior importância ao ser humano, e o relacionam como aquele capaz de explorar o meio ambiente. Nesse trabalho, concluímos que o aluno desenhava aquilo que ele "sabia" pertencer ao meio ambiente, mas, uma vez confrontado com as perguntas durante a entrevista, não estava certo de sua fala e não conseguia justificá-la.

Comparando-se os dados obtidos pela análise dos desenhos com os resultados das análises das entrevistas, identificamos resultados complementares, embora expressos por meio de dois instrumentos metodológicos distintos, a saber:

1. Não há diferença expressiva na percepção de meio ambiente por alunos de turmas de $1^{\circ}$ e $5^{\circ}$ anos do Ensino Fundamental. Em geral, eles percebem os seguintes elementos em ordem de prioridade: flora, fauna e seres humanos;

2. Nas entrevistas, alunos da turma de $5^{\circ}$ ano demonstraram mais dúvidas comparativamente aos alunos da turma de $1^{\circ}$ ano. É possível que os alunos da turma de $5^{\circ}$ ano estejam em meio a um processo de maturação da aprendizagem a respeito do meio ambiente. Podemos ainda considerar a possibilidade de que esses alunos estejam no momento da aprendizagem proximal, como nos propõe Vygotsky (2007). Ou seja, alunos que apresentam dúvidas, mas com chance de esclarecimento e apoio direcional, poderão sedimentar corretamente determinado conhecimento ou ser estimulados para a reflexão.

\section{Análise das figuras}

Essa etapa da pesquisa teve como objetivo identificar possíveis soluções propostas, pelos alunos, frente a determinados problemas ilustrados em gravuras. 
Participaram, dessa etapa da pesquisa, 36 alunos, sendo 15 da turma de $1^{\circ}$ ano e 21 da turma de $5^{\circ}$ ano.

Gravuras apresentando problemas ambientais foram expostas a 12 grupos de três alunos. Após esse tempo, os alunos eram estimulados a sugerir possíveis soluções para os problemas que eventualmente haviam identificados. A participação de todos os alunos de cada grupo era fortemente estimulada pela pesquisadora. As gravuras se relacionavam aos mesmos temas tratados nas entrevistas, e foram expostas e discutidas na seguinte sequência:

1. Gravuras A, B, C - relacionadas ao tema "água";

2. Gravuras D, E, F - relacionadas ao tema "relações entre o sujeito e outras pessoas e cuidados que os sujeitos podem atribuir ao meio ambiente";

3. Gravuras G, H, I - relacionadas ao tema "lixo".

$\mathrm{Na}$ figuras 3, 4, 5 e 6 podemos observar algumas das gravuras expostas aos alunos.

Figura 3. Desperdício de água

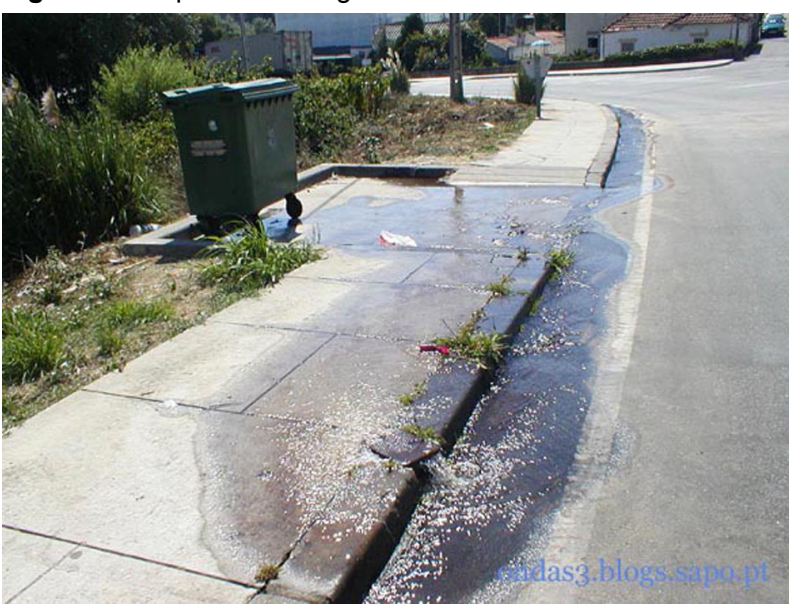

Fonte: Disponível em: <http://amanatureza.com/conteudo/artigos/ denuncie-desperdicio-agua>. Acesso em: 11 mar. 2011.

Figura 5. Relação com outros seres seres

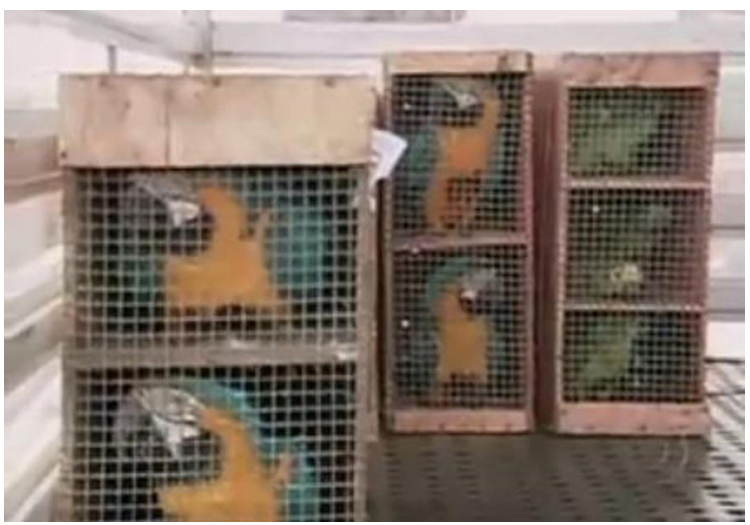

Fonte: Disponivel em: <http://www.bemmelhor.net/a-realidade-dotrafico-de-animais>. Acesso em: 11 mar. 2011.
Figura 4. Relações entre os sujeitos

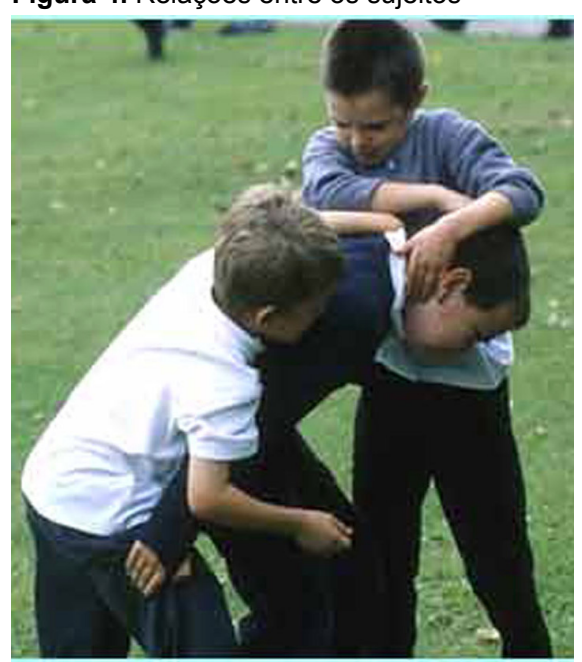

Fonte: Disponivel em: <http://websmed. portoalegre.rs.gov.br/escolas/liberato/psicologia/ AGRESSIVIDADE.htm>. Acesso em: 11 mar. 2011. 
Figura 6. Lixo

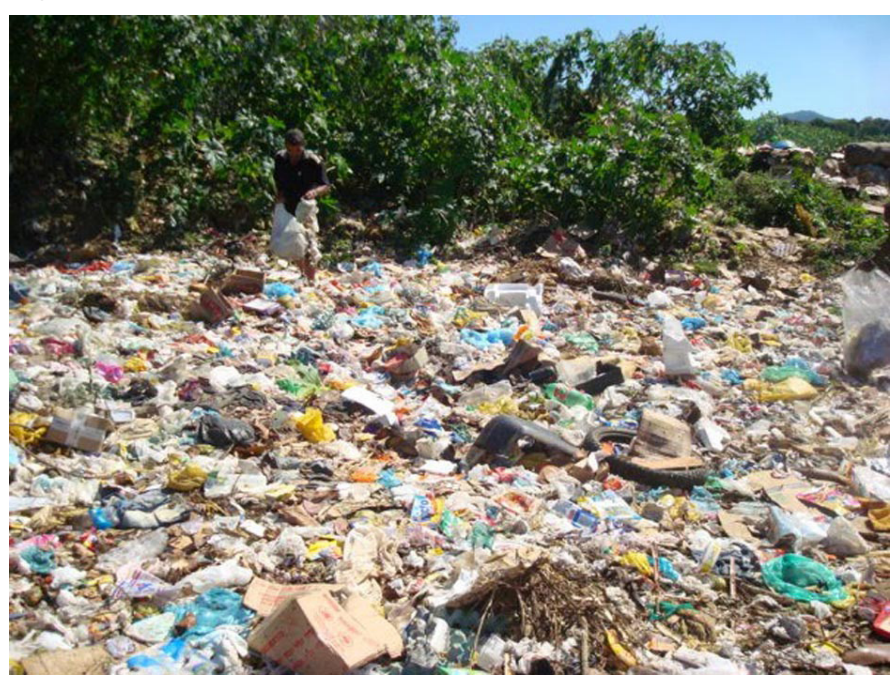

Fonte: Disponível em: <http://sustentabilidade-educacaoambiental.blogspot.com. br/2009/11/situacao-de-jequie.html>. Acesso em: 11 mar. 2011.

As conversas durante a exposição das gravuras foram categorizadas de acordo com análise de conteúdo sugerida por Bardin (2009). As soluções apresentadas pelos alunos foram registradas por escrito e, também, em gravador de voz, e categorizadas posteriormente. As sugestões para os problemas ambientais levantados a partir das gravuras foram categorizadas, assim como na entrevista, de acordo com os temas selecionados: "água", "lixo" e "relações entre o sujeito e outras pessoas, e cuidados que os sujeitos podem atribuir ao meio ambiente". No Quadro 1 é possível observar algumas das soluções apontadas pelos alunos.

Quadro 1. Soluções apontadas pelos alunos das turmas de $1^{\circ}$ e $5^{\circ}$ anos para os eventuais problemas identificados na análise de gravuras

\begin{tabular}{|c|c|c|}
\hline Gravuras & $1^{\circ}$ ano $(n=15)^{*}$ & $5^{\circ}$ ano $(n=21)$ \\
\hline A, B, C (tema: água) & $\begin{array}{l}\text { - Fechar a torneira (9) } \\
\text { - Tampar o bueiro }(9)\end{array}$ & $\begin{array}{l}\text { - Fechar a torneira (18) } \\
\text { - Economizar água (12) } \\
\text { - Tampar o bueiro (9) } \\
\text { - Chamar adultos (9) } \\
\text { - Construir poços (9) } \\
\text { - Ligar para bombeiro, prefeitura, Cedae (6) }\end{array}$ \\
\hline $\begin{array}{l}\text { D, E, F (tema: relações entre } \\
\text { o sujeito e outras pessoas e } \\
\text { cuidados que os sujeitos podem } \\
\text { atribuir ao meio ambiente) }\end{array}$ & $\begin{array}{l}\text { - Cultivar a amizade (6) } \\
\text { - Avisar aos pais (6) } \\
\text { - Chamar a polícia para } \\
\text { libertar os animais (3) }\end{array}$ & $\begin{array}{l}\text { - Denunciar os maus-tratos aos animais e } \\
\text { chamar a polícia (21) } \\
\text { - Separar a briga de colegas (9) } \\
\text { - Não provocar a violência (9) }\end{array}$ \\
\hline G, H, I (tema: lixo) & $\begin{array}{l}\text { - Jogar lixo na lixeira (9) } \\
\text { - Não jogar lixo no rio (6) }\end{array}$ & $\begin{array}{l}\text { - Não jogar lixo na rua (12) } \\
\text { • Solicitar o serviço de coleta (9) } \\
\text { • Não jogar lixo no valão (6) }\end{array}$ \\
\hline
\end{tabular}

Entre parênteses: número de alunos

Fonte: Elaborado pelas autoras a partir dos dados da pesquisa. 
Os alunos das turmas de $1^{\circ}$ e $5^{\circ}$ anos revelaram, por meio da análise das gravuras, preocupação com a convivência saudável entre os seres humanos e desses com outros seres vivos, além dos cuidados necessários com outros elementos do meio ambiente.

\section{Considerações finais}

Os resultados do trabalho permitem apontar que as percepções sobre o meio ambiente, de alunos de $1^{\circ}$ e $5^{\circ}$ anos do Ensino Fundamental, retratadas por meio de desenhos e de falas nas entrevistas sobre os desenhos, apontam, na sua grande maioria, para uma percepção naturalista, ou seja, meio ambiente como sinônimo de natureza, desligada dos contextos social, econômico, político e cultural nos quais se insere o ser humano. Embora os desenhos e as entrevistas sobre os desenhos apontem, majoritariamente, para uma visão naturalista do meio ambiente, quando os alunos são desafiados por imagens em gravuras que lhes permitem associações com problemas diversos, eles apresentam percepção mais complexa da realidade do ambiente que os cerca, tais como: escassez de áreas de lazer (praças e parques), coleta irregular de lixo e distribuição irregular de água.

Segundo Freire (2001), a leitura de mundo precede a leitura da palavra, ou seja, antes de o indivíduo dominar a leitura de uma palavra, ele já faz a leitura de mundo, por meio dos relacionamentos e de interações cotidianas. Os alunos pesquisados nesse estudo revelaram possuir a leitura de mundo abordada pelo autor. Nossos resultados revelam que, mesmo crianças em seu universo infantil, percebem fatos relacionados à sua vida, família e casa.

No presente trabalho, quando os alunos percebem problemas relacionados ao seu cotidiano, são capazes de verbalizar soluções e revelam disposição para interferir e agir em prol do seu bem-estar e de outros. Assim como Marx e Freire, que buscavam uma sociedade com qualidade de vida para todos, as soluções dos alunos para buscar melhorias em seu local de residência demonstram o desejo de construírem e viverem em uma sociedade melhor.

Conhecer a percepção de meio ambiente dos alunos, segundo Reigota (2009) e Brügger (2004), contribui muito para a elaboração de atividades em EA. Nesse trabalho, grande parte dos alunos demonstrou percepção naturalista de meio ambiente. Logo, os docentes desses alunos, ao planejarem atividades em EA, devem considerar esses resultados a fim de construir, coletivamente com os alunos, um conceito de meio ambiente mais amplo.

Esperamos que os resultados de nosso estudo possam ressaltar a importância da Educação Ambiental Crítica nas séries iniciais do Ensino Fundamental, além de auxiliar no planejamento de programas e atividades em EA a partir do conhecimento da percepção de meio ambiente apontada pelos alunos. 


\section{Referências}

AIRES, B. F. C.; BASTOS, R. P. Representações sobre meio ambiente de alunos da educação básica de Palmas (TO). Ciência \& Educação, Bauru, v. 17, n. 2, p. 353-364, 2011. Disponível em: <http://dx.doi.org/10.1590/S1516-73132011000200007>. Acesso em: 25 jun. 2014.

BARCELLOS, P. A. O. et al. As representações sociais dos professores e alunos da Escola Municipal Karla Patrícia, Recife, Pernambuco, sobre o manguezal. Ciência \& Educação, Bauru, v. 11, n. 2, p. 213-222, 2005. Disponível em: <http://dx.doi.org/10.1590/S1516-73132005000200005>. Acesso em: 25 jun. 2014.

BARDIN, L. Análise de conteúdo. São Paulo: Edições 70, 2009.

BASTOS, V. P. Jardim Gramacho e o território do lixo. In: NÚCLEO INTERDISCIPLINAR DE MEIO AMBIENTE. Educação ambiental: formação de valores ético-ambientais para o exercício da cidadania no município de Duque de Caxias. Rio de Janeiro: [s.n], 2009. p. 119-134.

BELLINGHAUSEN, I. B. Vamos abraçar o mundinho. São Paulo: DCL, 2002.

BISPO, M. O.; OLIVEIRA, S. F. Lugar e cotidiano: categorias para compreensão de representações em meio ambiente e educação ambiental. Revista Brasileira de Educação Ambiental, Cuiabá, v. 2, n. 2, p. 69-76, 2007.

BRASIL. Ministério da Educação e do Desporto. Secretaria de Educação Fundamental. Parâmetros curriculares nacionais: meio ambiente e saúde. Brasília, 1997.

BRÜGGER, P. Educação ou adestramento ambiental? 3. ed. rev. Chapecó: Letras Contemporâneas, 2004.

FREIRE, P. Carta de Paulo Freire aos professores. Estudos Avançados, São Paulo, v. 15, n. 42, p. 259-268, 2001. Disponível em: <http://dx.doi.org/10.1590/eav.v15i42.9805>. Acesso em: 25 jun. 2014.

FREIRE, P. Pedagogia do oprimido. Rio de Janeiro: Paz e Terra, 2005.

GUIMARÃES, M. Diagnóstico da percepção sócio-ambiental de professores em Xerém (Duque de Caxias/RJ) e as relações com o processo de modernização. In: ENCONTRO DA ASSOCIAÇÃO NACIONAL DE PÓS GRADUAÇÃO E PESQUISA EM AMBIENTE E SOCIEDADE, 1., 2002, Indaiatuba. Anais... Indaiatuba: ANPPAS, 2002. Disponível em: <http://www.anppas.org.br/ encontro_anual/encontro1/gt/sociedade_do_conhecimento/Mauro\%20Guimaraes.pdf $>$. Acesso em: 25 jun. 2014.

GUIMARÃES, M. Educação ambiental: participação para além dos muros da escola. In: MELLO, S. S.; TRAJBER, R. (Coord.). Vamos cuidar do Brasil: conceitos e práticas em educação ambiental na escola. Brasília: Ministério da Educação: Ministério do Meio Ambiente: UNESCO, 2007. p. 85-93.

GUIMARÃES, M. Educação ambiental crítica. In: LAYRARGUES, P. P. (Org.). Identidades da educação ambiental brasileira. Brasília: Ministério do Meio Ambiente, 2004. p. 25-34.

HOEFFEL, J. L.; FADINI, A. A. B. Percepção ambiental. In: ENCONTROS e caminhos: formação de educadoras(es) e coletivos educadores. Brasília: Departamento de Educação Ambiental, 2007. v. 2, p. 253-262. Disponível em: <http://www.mma.gov.br/estruturas/educamb/_arquivos/encontros_2. pdf $>$. Acesso em: 25 jun. 2014. 
LOUREIRO, C. F. B. Educação ambiental crítica: contribuições e desafios. In: MELLO, S. S.; TRAJBER, R. (Coord.). Vamos cuidar do Brasil: conceitos e práticas em educação ambiental na escola. Brasília: Ministério da Educação: Ministério do Meio Ambiente: UNESCO, 2007. p. 65-71.

LOUREIRO, C. F. B. Educação ambiental transformadora. In: LAYRARGUES, P. P. (Org.).

Identidades da educação ambiental brasileira. Brasília: Ministério do Meio Ambiente, 2004. p. 65-84.

LOUREIRO, F. Karl Marx: história, crítica e transformação social na unidade dialética da natureza. In: CARVALHO, I. C. M.; GRÜN, M.; TRAJBER, R. (Org.). Pensar o ambiente: bases filosóficas para a educação ambiental. Brasília: Ministério da Educação: UNESCO, 2006. p. 125-137.

LUDKE, M.; ANDRÉ, M. E. D. A. Pesquisa em educação: abordagens qualitativas. São Paulo: EPU, 1986.

MARIN, A. A.; OLIVEIRA, H. T.; COMAR, V. A educação ambiental num contexto de complexidade do campo teórico da percepção. Interciencia, Caracas, v. 28, n. 10, p. 616-619, 2003. Disponível em: <http://www.scielo.org.ve/scielo.php?pid=S0378-18442003001000012\&script=sci_ arttext>. Acesso em: 25 jun. 2014.

MARTINHO, L. R.; TALAMONI, J. L. B. Representações sobre meio ambiente de alunos da quarta série do ensino fundamental. Ciência \& Educação, Bauru, v. 13, n. 1, p. 1-13, 2007. Disponível em: <http://dx.doi.org/10.1590/S1516-73132007000100001>. Acesso em: 25 jun. 2014.

MARX, K. O trabalho alienado. In: Economia política e filosofia. Rio de Janeiro: Melso, 1963. p. 317-340.

MORIN, E.; CIURANA, E. R.; MOTTA, R. D. Educar na era planetária: o pensamento complexo como método de aprendizagem pelo erro e incerteza humana. 3. ed. São Paulo: Cortez; Brasília: UNESCO, 2009.

NEVES, J. L. Pesquisa qualitativa: características, usos e possibilidades. Cadernos de Pesquisas em Administração, São Paulo, v. 1, n. 3, p. 1-5, 1996. Disponível em: <http://www.dcoms.unisc. $\mathrm{br} /$ portal/upload/com_arquivo/pesquisa_qualitativa_caracteristicas_usos_e_possibilidades.pdf $>$. Acesso em 25 jun. 2014.

PEDRINI, A.; COSTA, E. A.; GHILARDI, N. Percepção ambiental de crianças e pré-adolescentes em vulnerabilidade social para projetos de educação ambiental. Ciência $\boldsymbol{\&}$ Educação, Bauru, v. 16, n. 1, p. 163-179, 2010. Disponível em: <http://dx.doi.org/10.1590/S1516-73132010000100010>. Acesso em: 25 jun. 2014.

PEREIRA, L. T. K. O desenho infantil e a construção da significação: um estudo de caso. Disponível em: < http://portal.unesco.org/culture/en/files/29712/11376608891lais-krucken-pereira. pdf/lais-krucken-pereira.pdf >. Acesso em: 27 set. 2011.

PERNAMBUCO, M. M.; SILVA, A. F. G. Paulo Freire: a educação e a transformação do mundo. In: CARVALHO, I. C. M.; GRÜN, M.; TRAJBER, R. (Org.). Pensar o ambiente: bases filosóficas para a educação ambiental. Brasília: Ministério da Educação: UNESCO, 2006. p. 207-219.

PINOTTI, R. Educação ambiental para o século XXI: no Brasil e no mundo. São Paulo: Blucher, 2010.

QUINTAS, J. S. Educação no processo de gestão ambiental: uma proposta de educação ambiental transformadora e emancipatória. In: LAYRARGUES, P. P. (Org.). Identidades da educação ambiental brasileira. Brasília: Ministério do Meio Ambiente, 2004. p. 113-140. 
REIGADA, C.; TOZONI-REIS, M. F. C. Educação ambiental para crianças no ambiente urbano: uma proposta de pesquisa-ação. Ciência \& Educação, Bauru, v. 10, n. 2, p. 149-159, 2004. Disponível em: <http://dx.doi.org/10.1590/S1516-73132004000200001>. Acesso em: 25 jun. 2014.

REIGOTA, M. Meio Ambiente e representação social. São Paulo: Cortez, 2007.

REIGOTA, M. O que é educação ambiental. 2. ed. rev. São Paulo: Brasiliense, 2009.

SCHWARZ, M. L.; SEVEGNANI, L.; ANDRÉ, P. Representações da Mata Atlântica e de sua biodiversidade por meio dos desenhos infantis. Ciência \& Educação, Bauru, v. 13, n. 3, p. 369-388, 2007. Disponível em: <http://dx.doi.org/10.1590/S1516-73132007000300007>. Acesso em: 25 jun. 2014.

SOUZA, D. V.; ZIONI, F. Novas perspectivas de análise em investigações sobre meio ambiente: a teoria das representações sociais e a técnica qualitativa da triangulação de dados. Saúde e Sociedade, São Paulo, v. 12, n. 2, p. 76-85, 2003.

TOZONI-REIS, M. F. C. Temas ambientais como "temas geradores": contribuições para uma metodologia educativa ambiental crítica, transformadora e emancipatória. Educar em Revista, Curitiba, n. 27, p. 93-110, 2006. Disponível em: <http://dx.doi.org/10.1590/S010440602006000100007>. Acesso em: 15 jan. 2011.

TOZONI-REIS, M. F. C. Educação ambiental: natureza, razão e história. 2. ed. rev. Campinas: Autores Associados, 2008.

VIGOTSKY, L. S. A formação social da mente: o desenvolvimento dos processos psicológicos superiores. 7. ed. São Paulo: Martins Fontes, 2007.

VIGOTSKY, L. S. Pensamento e linguagem. 2. ed. São Paulo: Martins Fontes, 1989. 